\title{
Caesarean scar ectopic pregnancy of 12 weeks: a rare and unexpected long-term complication of caesarean section
}

\author{
Priti Agrawal $^{1 *}$, Rishi Agrawal' ${ }^{2}$ Sujeet Agrawal ${ }^{3}$
}

\begin{abstract}
${ }^{1}$ Department of Obstetrics, Gynecology and Infertility, Aarogya Hospital and Test Tube Center, Raipur, Chhattisgarh, India

${ }^{2}$ Department of General and Laparoscopic Surgery, Aarogya Hospital and Test Tube Center, Raipur, Chhattisgarh, India

${ }^{3}$ Department of Radiology, Shri Shyam Diagnostic Center, Ambikapur, Chhattisgarh, India
\end{abstract}

Received: 08 September 2020

Accepted: 08 October 2020

\section{*Correspondence:}

Dr. Priti Agrawal,

E-mail: drpritiagrawal15@gmail.com

Copyright: (c) the author(s), publisher and licensee Medip Academy. This is an open-access article distributed under the terms of the Creative Commons Attribution Non-Commercial License, which permits unrestricted non-commercial use, distribution, and reproduction in any medium, provided the original work is properly cited.

\begin{abstract}
Caesarean scar ectopic pregnancy (CSEP) is one of the rarest of all ectopic pregnancies. CSEP is a life-threatening condition and should be timely diagnosed and managed because if left untreated, it may lead to serious complications like uterine rupture, hemorrhage, hypovolemic shock and even maternal death. A 29-year-old female with history of amenorrhea 3 months, was referred from remote rural area with severe abdominal pain and vaginal bleeding for 15 days. Her previous childbirth was by caesarean section (CS), 4 years back. Trans abdominal ultrasonography (USG) revealed gestational sac in lower uterine segment and attached to anterior wall. Upper uterine segment was empty, crown lump length was $5.86 \mathrm{~cm}$ corresponding to 12 weeks and 3 days. As the pregnancy was 12 weeks with very thin myometrium covering it and placenta fully covering internal orifice of the cervix uteri (internal OS), took decision for laparotomy. Vaginal bleeding and abdominal pain are the most common presenting symptoms of CSEP. Severe acute abdominal pain or heavy vaginal bleeding may indicate impending rupture while hemodynamic instability may indicate rupture of CSEP. Laparoscopy or laparotomy can be done in such cases to remove pregnancy. Chose laparotomy as it would give quick, better access and control of hemorrhage in this case. The risk of CSEP and placenta accrete should be specially emphasized when counselling women requesting CS for nonmedical reasons. Prompt and accurate diagnosis using transvaginal ultrasonography (TVUS) followed by individualized treatment will significantly help to reduce morbidity related to CSEP.
\end{abstract}

Keywords: Abortion, Ectopic pregnancy, CS, Transabdominal and transvaginal ultrasound, Hemorrhage

\section{INTRODUCTION}

CSEP is one of the rarest of all ectopic pregnancies. The first case was reported in 1978 and incidence of CSEP ranges from $1 / 1800$ to $1 / 2500$ of all pregnancies and accounts for $6 \%$ of all ectopic pregnancies. ${ }^{1-4}$

The pregnancies with previous CS have increased the risk of placenta previa, placental abruption, placenta accrete, percreta and scar ectopic pregnancies. CSEP is a lifethreatening condition and should be timely diagnosed and managed because if left untreated, it may lead to serious complications like uterine rupture, hemorrhage, hypovolemic shock, disseminated intravascular coagulation and even maternal death.

The gold standard for diagnosing CSEP is TVUS which may be combined with a transabdominal scan for panoramic view.

There are various theories which explain the etiology and mechanism of CSEPs. Type I: CSEP, develops in the 
myometrium and grows towards the uterine cavity whereas, Type II: CSEP, progresses exophytically towards the uterine serosa. If left untreated massive hemorrhage may even necessitate hysterectomy to prevent maternal death. Treatment modalities are dependent on the case presentation and can be managed expectantly, medically with methotrexate or surgically. In principle, pregnancy should be ended as soon as possible after confirming the diagnosis, with the aim of removing the gestational sac and the CSEP to retain future fertility. Report a case of 12 weeks of CSEP managed by laparotomy where hemorrhage occurred due to placenta covering the internal OS, managed efficiently, thus saving major morbidity or even mortality.

\section{CASE REPORT}

A 29-year-old female with history of amenorrhea 3 months, was referred from remote rural area with abdominal pain and vaginal bleeding for 15 days. Her previous childbirth was by CS, 4 years back. She had undergone routine antenatal TVUS at 8 weeks of pregnancy at her native place where it was detected that gestational sac was low lying covered by thin myometrium, corresponding to the scar site of previous CS, uterine cavity was empty with thick endometrium. Cervical canal was closed and empty (Figure 1). Findings were suggestive of CSEP but patient was not convinced of this rare entity as she did not have any problems like pain in abdomen or vaginal bleeding. She went back to home. After 15 days she had mild pain in abdomen and vaginal bleeding but she tolerated it. She reached hospital after one month of initial diagnosis when pain in abdomen and bleeding per vaginum increased. A repeat sonography was done confirming the diagnosis of CSEP of 12 weeks gestational age. And treating doctor referred her to higher center.

On physical examination her pulse, blood pressure and all vitals were stable. Her cardiorespiratory and neurological system were normal. Her abdomen was soft and not tender. Speculum examination revealed a normal cervix with minimal bleeding and without cervical dilation and ballooning. Pelvic examination revealed approximately 12 to 14 weeks size uterus, soft in consistency, cervical movements were not tender.

Transabdominal uterus revealed gestational sac in lower uterine segment and attached to anterior wall. Upper uterine segment was empty (Figure 1B), crown lump length was $5.86 \mathrm{~cm}$ corresponding to 12 weeks and 3 days. The myometrium overlying the sac was markedly thin measuring $2.2 \mathrm{~mm}$. Placenta was anterior and covering the internal OS completely. Internal and external OS were closed and cervical length was $3.5 \mathrm{~cm}$ with no ballooning. There was significant vascularity in the anterior myometrial wall on doppler (Figure $1 \mathrm{C}$ and D). All features were suggestive of CSEP.
As the pregnancy was 12 weeks with very thin myometrium covering it and placenta fully covering internal OS, took decision for laparotomy. Abdomen was opened by previous Pfannenstiel CS scar. Upper uterine segment was empty and extremely soft like a sponge easily compressed between fingers and gestational sac was in lower uterine segment covered with thin myometrium (Figure 2A). Incision was given over the bulge with knife, fetus and placenta, covering the internal OS were removed gently (Figure2B). After removing placenta, profuse hemorrhage started from the placental bed which was controlled by hemostatic sutures and bilateral uterine arteries were ligated. After hemostasis, repair of the scar done in two layers with vicryl suture. Uterotonics were given but upper uterine segment didn't gain adequate uterine tone and so modified B-Lynch sutures were applied. Intraoperative blood loss was 400 $\mathrm{ml}$ and patient was stable. After adequate uterine tone, abdomen was closed in layers. One unit of blood transfusion was given. Postoperative period was uneventful and patient was discharged on fourth postoperative day. Patient has been advised oral contraceptive pills to delay further childbearing for at least 2 years. The patient came for follow-up at 6 weeks and 3 months postoperatively with no problems.

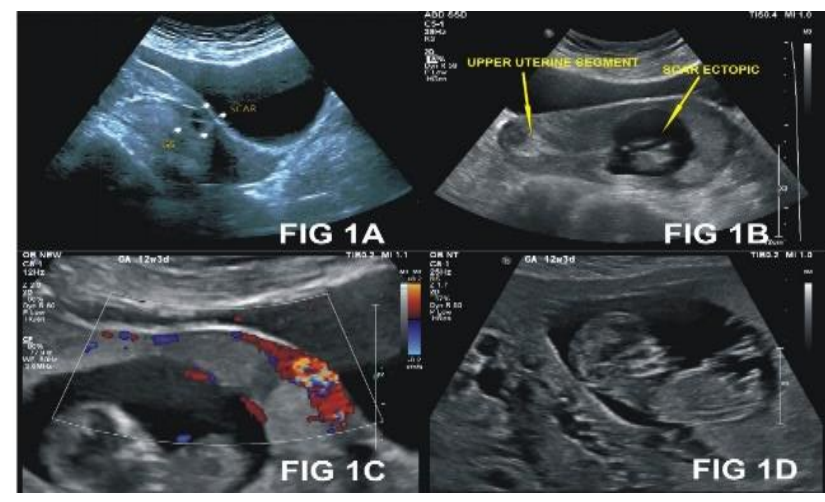

Figure 1: (A) Gestational sac in lower uterine segment, (B) 12 weeks pregnancy upper uterine segment empty, (C) Doppler of high vascularity in lower uterine segment, (D) Internal OS closed.

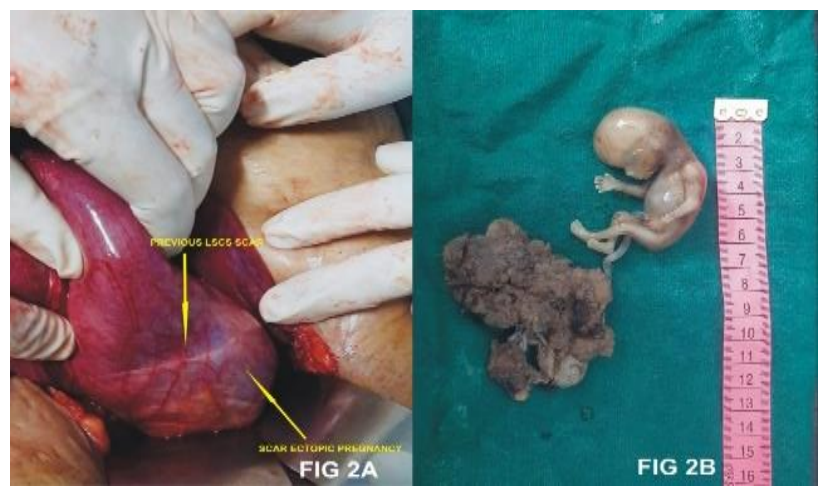

Figure 2: (A) Intraoperative picture of scar ectopic, (B) Removed fetus and placenta. 


\section{DISCUSSION}

Vaginal bleeding and abdominal pain are the most common presenting symptoms of CSEP. The patient could tolerate the pain for about one month as the pregnancy was growing towards uterine cavity. Severe acute abdominal pain or heavy vaginal bleeding may indicate impending rupture while hemodynamic instability may indicate rupture of CSEP through the myometrium Fenerty et al reported CSEP in a case of previous $3 \mathrm{CS}$ where patient had only intermittent vaginal bleeding with no abdominal pain, fever or dysuria. The patient had not undergone any intervention from 8 to 12 weeks of pregnancy. ${ }^{5}$ Gupta et al reported a case where patient had history of dilation and curettage in view of incomplete abortion and histopathology revealed hyperplastic endometrium with no villi. ${ }^{6}$ Pregnancy continued and then laparotomy was done and CSEP was removed.

Establishing a diagnosis CSEP is challenging but in this case using the criteria given by Timor-Tritsch it was diagnosed easily. ${ }^{7}$

The seven criteria proposed by Timor et al are as follows:- An empty uterine cavity and an empty endocervical canal, a gestational sac located in the anterior portion of the lower uterine segment corresponding to the scar site of the previous caesarean, demonstration of functional trophoblastic tissue by doppler ultrasound at the site of implantation at the scar, In early gestation, less than 8 weeks, a triangular shaped gestational sac filling the scar niche (after 8 weeks of gestation a rounded or an oval sac could be observed), cervical canal that is closed and empty, observation of fetal pole and or yolk sac with or without heart activity and absence or deficiency of a healthy myometrium between the bladder and the gestational sac.

The CSEP are misdiagnosed as either inevitable miscarriages with low lying sac or cervical pregnancies gentle pressure at the level of the internal cervical OS may displace the gestational sac, thus demonstrating what is known as the sliding sign. The sliding sign is typically absent in CSEP and cervical ectopic pregnancy. A cervical pregnancy is present in OS close to the cervical canal, with ballooning of the cervix. ${ }^{8}$

MRI is also a useful tool to demonstrate involvement of adjacent organs such as urinary bladder and abnormalities of placentation. MRI optimally demonstrates findings of placenta accreta spectrum, which may include thinning or absence of the sub placental myometrium, aberrant vessels, focal bulging of the uterine contour, invasion of the urinary bladder or anterior abdominal wall. But in this case MRI was not done because of clear findings on USG.

Management of CSEP depends on gestational age and size, severity of implantation anomaly, clinical stability and patient desire for future fertility. In our case we chose laparotomy and surgical excision. USG has revealed placenta completely covering the OS with thin overlying myometrium so if we would have attempted dilation or curettage or hysteroscopy guided removal then there was high risk of torrential hemorrhage, incomplete evacuation, uterine rupture and injury to bladder.

Laparoscopy or laparotomy can be done in such cases to remove pregnancy. Chose laparotomy as it would give quick, better access and control of hemorrhage in this case Majangara et al also performed laparotomy in their case of CSEP, type II. ${ }^{9}$

Koplay et al did laparoscopy in their case of CSEP and found that the gestational sac was deeply impacted. Therefore, after confirming the location of sac using TVUS, they successfully vacuum aspirated the sac under laparoscopic guidance. ${ }^{10}$

The risk of recurrent scar ectopic pregnancy is low, 3.2 to $5 \% .{ }^{8}$ Women who intend to continue childbearing should be informed to avoid pregnancy for 12-24 months, in view of scar healing by fibrosis. If there is persistent defect with a thin myometrium over the scar, re-suturing of the defect can be considered prior to the next pregnancy. In future pregnancies, early ultrasound should be done to rule out recurrence. Even with an intrauterine pregnancy, the woman is still at risk of complications of multiple hysterotomies, abnormally adherent placenta, uterine rupture, massive hemorrhage and hysterectomy.

\section{CONCLUSION}

CSEP through rare, are now seen with increasing frequency as elective CSs have become more common and attempted vaginal deliveries following prior CS have declined. The risk of CSEP and placenta accrete should be specially emphasized when counselling women requesting $\mathrm{CS}$ for nonmedical reasons. Prompt and accurate diagnosis using TVUS followed by individualized treatment will significantly help to reduce morbidity related to CSEP.

\section{Funding: No funding sources \\ Conflict of interest: None declared \\ Ethical approval: Not required}

\section{REFERENCES}

1. Larsen JV, Soloman MH. Pregnancy in a uterine scar sacculus-an unusual cause of post abortal hemorrhage. S Afr Med J. 1978;53:142-3.

2. Seow KM, Huang LW, Lin YH, Lin MY, Tsai YL, Hwang JL. Cesarean scar pregnancy issues in management. Ultrasound Obstet Gynecol. 2004;23:247-53.

3. Jurkovic D, Hillaby K, Woelfer B, Lawrence A, Salim R, Elson CJ. First trimester diagnosis and management of pregnancies implanted into the lower 
uterine segment cesarean section scar. Ultrasound Obstet Gynecol. 2003;21:220-7.

4. Molinaro TA, Barnhart KT. Ectopic pregnancies in unusual locations. Sem Reprod Med. 2007;25(2):123-30.

5. Fenerty S, Gupta S, Anoakar J, Patel T. Cesarean scar ectopic pregnancy. Appl Radiol. 2017;46(12):20-21.

6. Gupta DT, Wahi S. A Rare Case report of cesarean scar ectopic pregnancy. J Clin Diagn Res. 2017;11(8):10-11.

7. Timor-Tritsch IE, Monteogrido A, Santos R, Tsymbal T, Pineda G, Arslan AA. The diagnosis, treatment and folloeup of cesarean scar pregnancy. Am J of Obstet Gynecol. 2012;207(1):44.

8. Jayaram PM, Okunoye GO, Konje J. Cesarean scar ectopic pregnancy: diagnostic challenges and management option. Obstet Gynecol. 2017;19(1):1320.
9. Majangara R, Madziyire MG, Verenga C, Manase M. Cesarean Section scar ectopic pregnancy-a management conundrum; a case report. J Medical case rep. 2019;13:137.

10. Koplay M, Dogan NU, Sivrim M, Erdogan H, Dogan S, Celik C. Ectopic pregnancy in a Cesarean Section scar: successful management using vacuum Aspiration under laproscopic Supervision-mini Review of Current Literature. Case Rep Surg. 2016;2016:4.

Cite this article as: Agrawal P, Agrawal R, Agrawal S. Caesarean scar ectopic pregnancy of 12 weeks: a rare and unexpected long-term complication of caesarean section. Int J Reprod Contracept Obstet Gynecol 2020;9:4773-6. 